\title{
Life-cycle phenotypic composition and mortality of Calanoides acutus (Copepoda: Calanoida) in the Scotia Sea: a modelling approach
}

\author{
G. A. Tarling*, R. S. Shreeve, P. Ward, A. Atkinson, A. G. Hirst \\ British Antarctic Survey, Natural Environment Research Council, High Cross, Madingley Rd, Cambridge CB3 0ET, UK
}

\begin{abstract}
A modelling approach was developed to identify the most likely composition of lifecycle phenotypes and mortality rates for Calanoides acutus found within the Scotia Sea. A stage- and age-structured model was parameterised with independent measurements of early copepodite stage duration, growth rate during the productive period and mortality and weight loss during the overwintering period. Four possible life-phenotypes were simulated, varying according to whether (1) they spent their first winter as a CIV or CV stage, and (2) they persisted for between one and several years. The mortality rate coefficient during the epipelagic period was allowed to vary between 0.01 and $0.1 \mathrm{~d}^{-1}$. Model runs determined the effect of all possible combinations of these variables on the abundance of the late copepodite stages, and predictions were compared to a comprehensive empirical data set, encompassing observations made over the last $60 \mathrm{yr}$. Best fits were achieved when $70 \%$ of the Scotia Sea population overwintered as a CV stage and $30 \%$ as CIV, with the majority of individuals reaching adulthood in their first year (after 1 overwintering period). During the epipelagic period, the population experienced mortality rate coefficients close to $0.06 \mathrm{~d}^{-1}$. This high rate makes it unlikely that the earliest recruits survive to the end of the productive season. Predation was responsible for over $80 \%$ of mortality during winter. Starvation, which made up the remainder, mostly affected individuals that were spawned late in the season. The total rate of overwintering mortality was less than $0.007 \mathrm{~d}^{-1}$. Sensitivity analyses demonstrated that model predictions were robust and identified the most likely causes of interannual and spatial variation in the observed data sets.
\end{abstract}

KEY WORDS: Copepod · Development · Antarctica $\cdot$ Population $\cdot$ Zooplankton $\cdot$ Life-history $\cdot$ Growth · Diapause

\section{INTRODUCTION}

Calanoides acutus is one of the most numerically abundant species of copepod in the Southern Ocean (Mackintosh 1934), and a main contributor to the zooplankton biomass of this region (Voronina 1970, 1978, Hopkins 1971, Huntley \& Escritor 1991, Pakhomov et al. 1997). It is primarily herbivorous and, together with other biomass-dominant copepods, may consume up to $55 \%$ of daily primary production (Pakhomov et al. 1997), so providing a major link between primary production and higher trophic levels. C. acutus is one of the few true diapausing species in the Southern
Ocean, with individuals entering a 7 to 9 mo long diapause, fuelled by extensive lipid reserves of wax ester (Drits et al. 1994). Fertilised females ascend to the upper water column in late winter, where they feed on the phytoplankton bloom and begin spawning. The development of the nauplii and early copepodite stages occurs in the near surface, and a downward migration of stages CIV and CV occurs during late summer/early autumn as feeding in the upper water column ceases.

At the end of winter, the fate of these overwintering stages is less clear, and thus the life cycle duration has remained the focus of considerable debate. Some 
authors suggest that the late copepodite stages moult through to adults, and so complete their life cycle in 1 yr (Voronina 1970, Marin 1988, Atkinson et al. 1997). However, studies undertaken by Drits et al. (1994) and Pasternak et al. (1994) suggest that individuals may remain in the late stages, accumulating lipids for a second summer, before entering diapause again and finally reaching maturity the following year. Copulation takes place in the deeper layers during late winter, and the males die soon after while the females ascend into the epipelagic layers and spawn.

In relation to the dynamics of the population, Atkinson et al. (1997) argued that, in a 1 yr life cycle, most Calanoides acutus would moult through to adults in the late winter, but in a 2 yr life cycle, most would remain as CIV or CV and dominate the population the following summer. Through compiling an extensive stage-frequency data set with seasonal data from 205 stations collected between 1928 and 1992, they concluded that $C$. acutus in the Scotia Sea normally completes its life cycle within 1 yr. However, Atkinson (1991) had previously noted that not all of the overwintering CIV and CVs moulted to adults in late winter, and their fate during the second summer was uncertain because these individuals became hard to separate from the new summer generation. Furthermore, in Fig. 5 of Atkinson et al. (1997), CV still accounted for between 10 and $50 \%$ of the population in spring (September to December), and must be left over from the previous season, and not be the result of recruitment during the current season, as development of younger copepodites does not proceed quickly enough to lead to a peak in CV at this time of year (Shreeve et al. 2002). Therefore, it seems that there must be a mixture of individuals with both 1 and 2 yr life cycles in the Scotia Sea population.

Calanoides acutus faces trade-offs in its life-history pattern. A 1 yr life cycle will minimise the amount of risk from predation an individual must endure before contributing to the next generation, but places greater pressure on it to achieve sufficient energy reserves in a limited amount of time to fuel overwintering, gonad development and reproduction the following spring. A life cycle lasting 2 yr or longer will allow individuals more time to amass energy reserves, but the likelihood of surviving to adulthood is smaller. The balance of the trade-off will depend on the rate of mortality in the epipelagic layer, as well as the rate of development and growth. We address these vital rates in a modelling study, using the empirical data set published by Atkinson et al. (1997) and more detailed data available on the stage duration of younger copepodite stages reported in Shreeve et al. (2002). The approach will lead to a prediction of the most likely composition of various life cycle phenotypes in the Scotia Sea population of C. acutus.

\section{MATERIALS AND METHODS}

Empirical data set. The empirical data set was the same as described by Atkinson et al. (1997). All available published and unpublished data on abundance and developmental stage structure between 30 and $80^{\circ} \mathrm{W}$ were used, encompassing the sub-Antarctic Front, the Polar Frontal Zone, the Polar Front and the Antarctic Zone. Atkinson et al. (1997) divided their data set into 'Scotia Sea', 'Weddell-Scotia Confluence' and 'Eastern Weddell Sea' and only stations falling in the first of these categories were used in the present study. Data were excluded if it was taken at a station with maximum depth of less than $1000 \mathrm{~m}$ or obtained with a net with a mesh that was coarser than $330 \mu \mathrm{m}$. Volume filtered was calculated either from flowmeter data or from the product of net mouth area and vertical distance. The final data set comprised of samples from 83 different times of year, each spaced an average of $4 \mathrm{~d}$ apart ( $\mathrm{SD}=7 \mathrm{~d}$ ). We assumed that every sample was taken from the same metapopulation.

Model design and implementation. The population model was initialised with the daily abundance of copepodite stage I (CI). This was achieved through an interpolation of the empirically derived abundances for this stage. A generic 3 parameter Gaussian function was fitted to the CI empirical data to produce the following definite function (see Table 1 for definition of terms):

$$
N_{d}=658.85 \mathrm{e}^{\left[-0.5\left(\frac{d-146.93}{18.05}\right)^{2}\right]} \quad \mathrm{r}^{2}=0.29
$$

Because this approach has the effect of averaging the CI empirical data, it was considered that the abundances predicted by this function represented individuals that were, on average, already half way through the duration of this developmental stage.

A stage-structured model was constructed in the style of a Lefkovitch matrix (Lefkovitch 1965), incorporating information on development stage and age; this is a stage- and age-structured model (SASM) according to Carlotti et al. (2000). A separate weight structured model (WSM) was constructed in parallel, which was referred to by the SASM when assessing which mortality rates to apply to the population. The model progressed in $1 \mathrm{~d}$ increments. For early copepodid stages, movement from one developmental stage to the next occurred at ages determined from laboratory incubations (Shreeve 2002, Shreeve et al. 2002). For the later stages, which have the potential to enter a state of diapause and overwinter, this depended on the designated phenotype of the animal.

General model structure and determination of mortality rates of early copepodite stages: Mortality rates can be fitted to population data where stage 
Table 1. Definitions of symbols used in model

\begin{tabular}{|c|c|c|c|}
\hline Symbol & Description & Unit & Source \\
\hline$N_{d}$ & No. of individuals per day & Ind. $\mathrm{m}^{-2} \mathrm{~d}^{-1}$ & \\
\hline$t$ & Time & $\mathrm{d}$ & \\
\hline day & Day of the year (Day 1 = 1 Aug; max = 365) & $\mathrm{d}$ & \\
\hline$N_{\text {obs }}$ & Observed depth-integrated population concentration & Ind. $\mathrm{m}^{-2}$ & \\
\hline$N_{\text {pre }}$ & Predicted depth-integrated population concentration & Ind. $\mathrm{m}^{-2}$ & \\
\hline age & Cumulative days since mid-stage CI & d & \\
\hline$\beta$ & Mortality coefficient & $\mathrm{d}^{-1}$ & $\begin{array}{l}\text { Atkinson et al. (1997) } \\
\text { for overwintering }\end{array}$ \\
\hline $\operatorname{stage}_{X}$ & Developmental stage $x ;$ total of 6 stages & & \\
\hline$C_{\text {mass }}$ & Mean carbon weight of developmental stage & $\mu \mathrm{g} \mathrm{C}$ & $\begin{array}{l}\text { Shreeve et al. (2002) } \\
\text { Shreeve (2002) }\end{array}$ \\
\hline $\begin{array}{l}\text { CI, CII, CIII } \\
\text { CIV, CV }\end{array}$ & Copepodite stages 1 to 5 & & \\
\hline $\operatorname{Pr}_{y}$ & $\begin{array}{l}\text { Proportion of phenotype } y \text { in population; } \\
4 \text { possible phenotypes }\end{array}$ & $\%$ & \\
\hline SS & Sum of squares difference & No units & Zar (1996) \\
\hline a & Bĕlehrádek slope for the response & Constant (no units) & Bĕlehrádek (1935) \\
\hline$\alpha$ & Bĕlehrádek temperature scale position of the response & Constant (no units) & Bĕlehrádek (1935) \\
\hline$b$ & Bĕlehrádek exponent & Constant (no units) & Bĕlehrádek (1935) \\
\hline$D$ & Developmental stage duration & d & \\
\hline$T$ & Temperature & ${ }^{\circ} \mathrm{C}$ & \\
\hline
\end{tabular}

duration has been determined independently (e.g. Eiane et al. 2002). This approach is possible for early copepodite stages of Calanoides acutus, which have relatively inflexible stage durations. Shreeve (2002) and Shreeve et al. (2002) determined the stage durations through on-board laboratory incubations at ambient sea temperature (Table 2). These were included in the parameterisation of a SASM as follows:

$$
N_{t+1, \text { age }+1}=N_{t, \text { age }} \mathrm{e}^{-\beta \times t}
$$

The model was initialised with the smoothed CI empirical data described above. Assuming that these individuals were, on average, mid-way through the CI stage, development into CII occurred after only $1 / 2$ of the full stage duration of $\sim 6 \mathrm{~d}$ had passed. The subsequent CII stage lasted a further $5 \mathrm{~d}$. At the end of the model run, the numbers of individuals within the designated ages of CI and CII were collected for each day as follows:

$$
N_{t, \text { stage }_{X}}=\sum N_{t, \text { age }}
$$

The model was compared to the empirical data through determining the sum of squares difference (SS) between predicted (pre) and observed (obs) values for each respective stage $(x)$ :

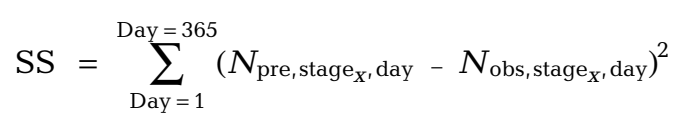

The model was iterated with different values for $\beta$ in Eq. (2) until a minimum SS value was achieved. A similar method was applied from CIII onwards but with modifications that allowed stage duration to be varied according to the phenotype of the animal.

Table 2. Calanoides acutus. Stage duration at $2.2^{\circ} \mathrm{C}$ (from Shreeve 2002, Shreeve et al. 2002, column 2) and age (cumulative days beyond mid-stage CI, column 3) in the 4 phenotypes (see 'Life-cycle phenotypes' for details) that potentially exist in the Scotia

\begin{tabular}{|c|c|c|c|c|c|c|}
\hline Stage & $\begin{array}{l}\text { Stage duration } \\
\text { (d) }\end{array}$ & $\begin{array}{l}\text { Cumulative days } \\
\text { beyond mid-CI }\end{array}$ & CIV 1 yr & CV 1 yr & CIV 2 yr & CV 2 yr \\
\hline CI & 6 & $3^{\mathrm{a}}$ & 3 & 3 & 3 & 3 \\
\hline CII & 5 & 8 & 8 & 8 & 8 & 8 \\
\hline CIII & 8 & 16 & 16 & 16 & 16 & 16 \\
\hline CIV & 14 & 30 & 244 & 30 & 258 & 30 \\
\hline $\mathrm{CV}$ & 228 & 258 & 258 & 258 & 623 & 623 \\
\hline Female & $\infty$ & $\infty$ & $\infty$ & $\infty$ & $\infty$ & $\infty$ \\
\hline
\end{tabular}
Sea population; values in columns 4-7 represent the maximum age (d) of an individual before it develops into the next stage according to phenotype 
Life-cycle phenotypes: Variable stage duration in the latter part of the life cycle was taken into account by allowing there to be 4 different life cycle phenotypes with different relative stage durations of copepodid stages CIV and CV (Table 2). The first 2 phenotypes exhibited 1 yr life cycles, with one phenotype (CIV 1 yr) over-wintering as a CIV stage, and the other (CV 1 yr) as a CV stage. The other 2 phenotypes exhibited 2 yr life cycles. In the first of these (CIV 2 yr), individuals spent the first winter as a CIV and the second winter as a CV, moulting from CIV to $\mathrm{CV}$ and from $\mathrm{CV}$ to adult in consecutive springs. In the other (CV 2 yr), individuals reached the $\mathrm{CV}$ stage by the first winter and remained in this stage for a further year before developing into adults the following spring. The stage durations of CI, CII and CIII were the same in all 4 phenotypes, as determined by Shreeve (2002). Where CIV was not an overwintering stage, its duration was set at $14 \mathrm{~d}$, as determined by this same study.

No studies have yet been carried out on sex determination in Calanoides acutus and there is little raw data available on the abundance of the males because they are short-lived and remain at depths below $500 \mathrm{~m}$. Therefore, it was necessary to make certain assumptions about sex-allocation for the purpose of model. We assumed that there was an equal probability of becoming either male or female and that both males and females were allowed to develop after either 1 or $2 \mathrm{yr}$, depending on phenotype. This was parameterised within the model through halving the population at the point that CV stages were due to develop into adulthood. One half was assumed to have developed into males and was discarded by the model, whilst the other half developed into females and was retained. This was necessary because the only reliable data for adults in the empirical data set was for females. The stage duration of adult females was set to infinity on the presumption that they were eventually removed from the population by natural mortality.

Seasonal vertical distribution: Calanoides acutus undergoes a seasonal migration from the epipelagic layer that it occupies during spring and summer to maximum depths in excess of $1000 \mathrm{~m}$ during the autumn and winter (Andrews 1966). Atkinson et al. (1997) synthesised data from a large number of cruises carried out in the Scotia Sea and plotted the median depth of the population, after grouping stations according to time of year, to determine seasonal vertical migration patterns and timings. Our interpolation of this plot showed that $C$. acutus left the epipelagic layer ( 0 to $200 \mathrm{~m}$ ) on 11 February and did not return until 3 November. Model runs were started from 1 August (Day 1) to remain consistent with previous empirical studies (e.g. Atkinson et al. 1997). Accordingly, descent occurred on Day 195 and reascent on Day 460.
Mortality rates during deep and epipelagic phases: The rate of predation experienced by copepod populations probably decreases once they have left the epipelagic layers. Atkinson et al. (1997) calculated that the mortality rate experienced by Calanoides acutus in the Scotia Sea during overwintering was $0.007 \mathrm{~d}^{-1}$. We assumed this mortality to be a combination of predation and starvation (see below). Once the population had returned to the epipelagic stratum the following spring, mortality was allowed to increase by between 2 and 15 times the overwintering predation rate (giving rates between 0.01 and $0.1 \mathrm{~d}^{-1}$ ), the exact amount depending on the model run. The upper limit of 15 times went far beyond that which gave the best fit to empirical data (see 'Results'), ensuring that all possible extremes were considered.

Rates of growth and weight-loss: Individuals were assumed to grow at a predetermined rate during their time in the epipelagic stratum. Mean weights of stages CI to CIV were obtained from Shreeve et al. (2002), while age was taken at the mid-point of each respective stage. CV covers both the period of growth (in the epipelagic layers) and weight-loss whilst overwintering at depth. It was necessary to estimate 2 further age/weight coordinates to predict growth in the epipelagic layers beyond CIV, first, average observed weight of $\mathrm{CV}$ against average time spent by $\mathrm{CV}$ in epipelagic layer and, second, maximum observed weight of $\mathrm{CV}$ against maximum possible time in epipelagic layer. Numbers of CI peaked on 25 December, resulting in the largest number of $\mathrm{CV}$ individuals appearing in the population on 24 January, i.e. $30 \mathrm{~d}$ later (Table 2). Given that the population descends on 11 February, the average CV will spend $18 \mathrm{~d}$ in the epipelagic layer, making its age-on-descent $48 \mathrm{~d}$ beyond mid-CI. The maximum possible time any individual can spend in the epipelagic layer was $105 \mathrm{~d}$ (see above). Shreeve et al. (2002) found the average weight of $\mathrm{CV}$ was $176 \mu \mathrm{g} \mathrm{C}$ and the maximum weight was $462 \mu \mathrm{g} \mathrm{C}$, when averaged over several cruises to the Scotia Sea during either spring or summer. These 2 age/weight coordinates for CV were combined with those for other developmental stages, and a 2-parameter growth equation was fitted (Eq. 5; Fig. 1).

$$
C_{\text {mass }}=0.6026 \times \text { age }^{1.429} \quad \mathrm{r}^{2}=0.99
$$

Individuals lose weight during overwintering because food intake is negligible, but metabolic costs must still be met. The rate of weight-loss can be calculated in 2 ways. The first is to determine the difference in weight at the start and end of overwintering. In a cruise undertaken at the start of the overwintering period, the average weight of CV stages (which may contain 2 yr olds as well as 1 yr olds) was $393 \pm 69 \mu \mathrm{g} \mathrm{C}$ (SD), whilst in a cruise taken at the end, average CV 


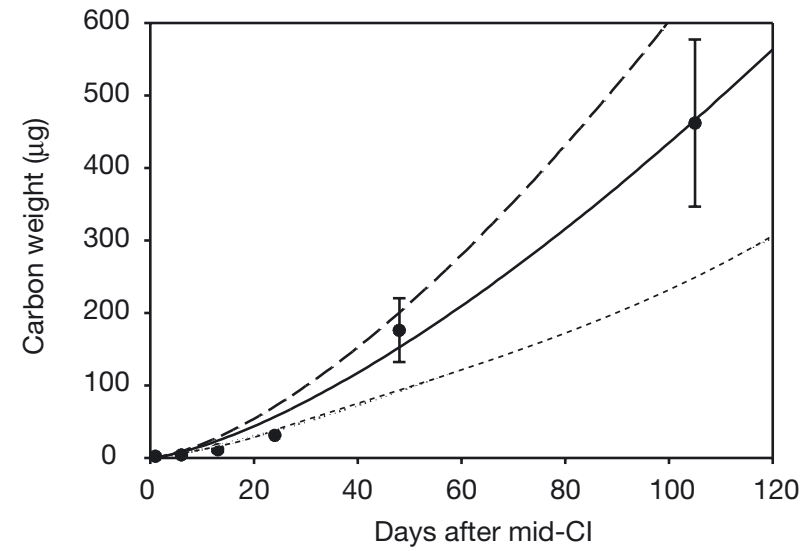

Fig. 1. Calanoides acutus. Predicted weight with age (solid line) fitted to the mean weight at mid-stage $(\bullet)$. Age of the last 2 points was inferred from average and maximum age on day of descent (see 'Rates of growth and weight loss'). Dashed and dotted lines illustrate, respectively, high and low growth rates used in sensitivity analyses. Bars denote $\pm 25 \%$ of mean value

weight was $91 \pm 26 \mu \mathrm{g} \mathrm{C}$ (SD, authors' unpubl. data). This is equivalent to a daily carbon loss of $0.25 \%$. The second way is to determine the metabolic rate. Pasternak et al. (1994) reported a 10 -fold decrease in metabolic rates in animals found at depths between 500 and $1000 \mathrm{~m}$ compared to those in the epipelagic layers. Given that 2.3 to $5.6 \%$ of body carbon is lost in respiration per day during the epipelagic period (Schnack et al. 1985), the metabolic demand during overwintering would be between 0.23 and $0.56 \%$ of body carbon, which is similar to the figure derived from the weightloss method above. Therefore, carbon loss during the overwintering period was set at $0.25 \%$ of body $\mathrm{C} \mathrm{d}^{-1}$.

Relative contribution of predation and starvation to overwintering mortality: The entire population reaches at least the CIV stage by the end of the overwintering period (Atkinson et al. 1997) whilst the observed mean weight of a CIV stage is $31 \mu \mathrm{g} C$ (Shreeve et al. 2002). Applying the above growth and shrinkage rates showed that any individual arriving at mid-stage CI after 12 January will ultimately shrink to below this weight before the end of the overwintering period. All of these individuals were therefore not considered to be able to reach the required 'critical weight' for viability and were subjected to an overwintering mortality rate that was too high for them to survive until the following spring $\left(0.06 \mathrm{~d}^{-1}\right)$.

It was assumed that predation and starvation were the principal causes of mortality during the overwintering period and an iterative method was used to calculate the relative contribution of each to the overall rate of $0.007 \mathrm{~d}^{-1}$. In the first step of this method, the survivorship $(S)$ of the population over the entire overwintering period was determined through applying a rate of $0.007 \mathrm{~d}^{-1}$. In the second step, this mortality was removed and replaced by the starvation mortality algorithms. For the final step, additional levels of mortality were added to the model until $S$ was equal to the initial run with $0.007 \mathrm{~d}^{-1}$. This additional mortality, $0.00585 \mathrm{~d}^{-1}$, was assumed to be equivalent to the rate of predation during overwintering. The rate of starvation is the difference between this and the overall mortality rate of $0.007 \mathrm{~d}^{-1}$, which was $0.00115 \mathrm{~d}^{-1}$.

Model run: Fig. 2 shows schematically how the different modules of the model connect to determine, eventually, the most likely make-up of the 4 potential life cycle phenotypes in the population. Initialisation of the model required the assignment of time- and stagedependent mortality rates, the number of individuals

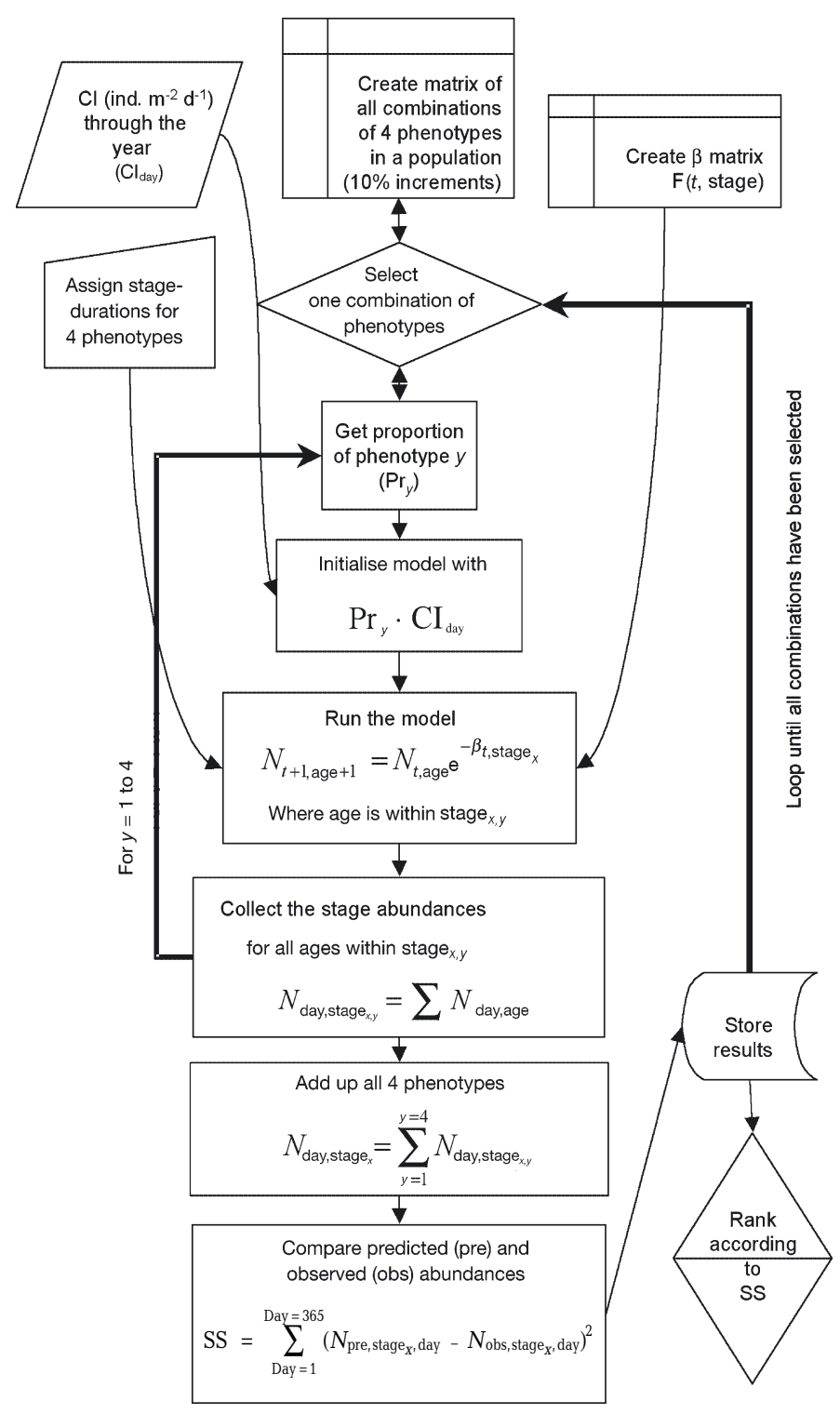

Fig. 2. Schematic of model. See Table 1 for definitions 


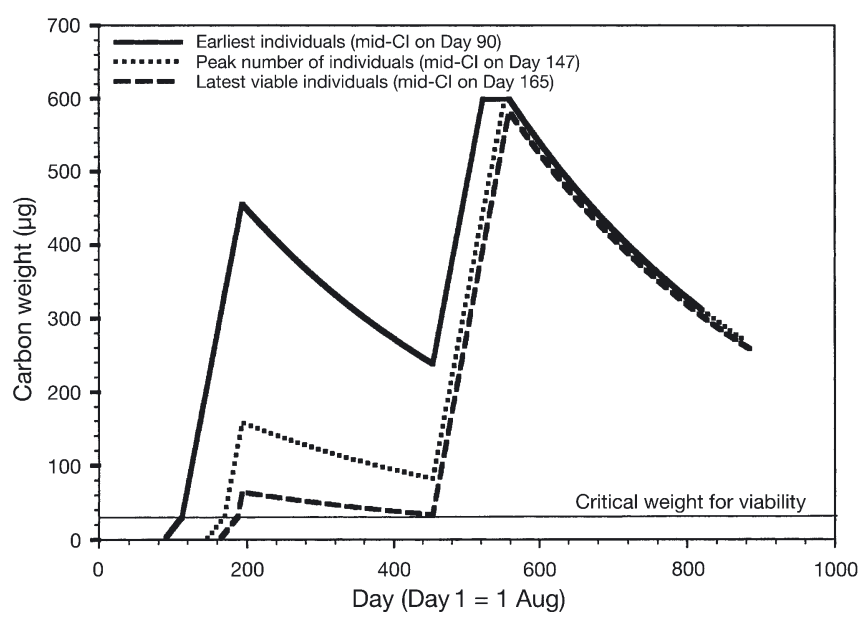

Fig. 3. Calanoides acutus. Weight trajectories of individuals entering mid-CI stage on different dates

(ind. $\mathrm{m}^{-2}$ ) entering into mid-stage CI per day over the entire recruitment period, and stage durations for each of the 4 life cycle phenotypes. A matrix of all possible combinations of 4 phenotypes in the population was created, each phenotype altering in $10 \%$ increments to make processing time manageable. This produced a total of 287 possible combinations. The model chose one of these combinations and then divided the CI population accordingly. Each of the 4 fractions were taken in turn and run through the model as described by Eqs. (2) \& (3), this time allowing individuals to pass beyond $\mathrm{CII}$ and develop according to their designated phenotype. Once all 4 phenotypes had been run through the model (i.e. until $t=1000$ ), their respective contributions were added together. Where $t=365 \mathrm{~d}$ or $730 \mathrm{~d}$, the day of the year (day) was reset to 1 . Individuals of the same stage on the same day of the year (irrespective of age) were added together to give a predicted daily concentration of each developmental stage on each day of the year. The data were validated against empirical observations and stored for ranking (see next section). The whole process was repeated with different levels of $\beta$ in the epipelagic period (up to 15 times the level of overwintering predation; see above).

Validation: The model output is the total abundance of individuals integrated through the entire water column, which can be as deep as $5000 \mathrm{~m}$ within the Scotia Sea. However, the empirical data set was mostly limited to a maximum depth of $1000 \mathrm{~m}$. Andrews (1966) found that a percentage of the Scotia Sea Calanoides acutus population descended below $1000 \mathrm{~m}$ during the overwintering period. This ranged from a minimum of $2 \%$ in December to a maximum of $30 \%$ in August. Reducing the predicted abundances by the percentage below $1000 \mathrm{~m}$ accommodated for this potential bias.
Extrapolating the monthly percentages given by Andrews (1966) to daily percentages was achieved through fitting a generic 4-parameter sine wave.

Predicted concentrations of individuals in each developmental stage were compared to observations according to Eq. (4). The total SS for each developmental stage was summed and stored for consequent ranking against other model runs that had different phenotypic compositions and/or different values for $\beta$ during the epipelagic period. The best fit was the run that achieved the highest average ranking in each developmental stage.

\section{RESULTS}

\section{Timing of reproduction}

The maximum predicted weight achieved by an individual before it descended out of the epipelagic layers depended on the time of year it entered the mid-CI stage (Fig. 3). The number of individuals arriving at the mid-CI stage increased from 29 October (Day 90) onwards, and individuals entering $\mathrm{CI}$ this early reached $462 \mu \mathrm{g} \mathrm{C}$ (the maximum observed weight of a CV stage) before descent. These individuals shrank to $238 \mu \mathrm{g} \mathrm{C}$ before re-ascending into the epipelagic layers the following spring, where they reached the maximum observed weight of an adult female (599 $\mu \mathrm{g}$ C) by 6 January (Day 524). Individuals that entered mid-CI during the peak recruitment period barely reached $1 / 3$ of the weight of early individuals by the time of descent in the first year. However, they did achieve maximum female

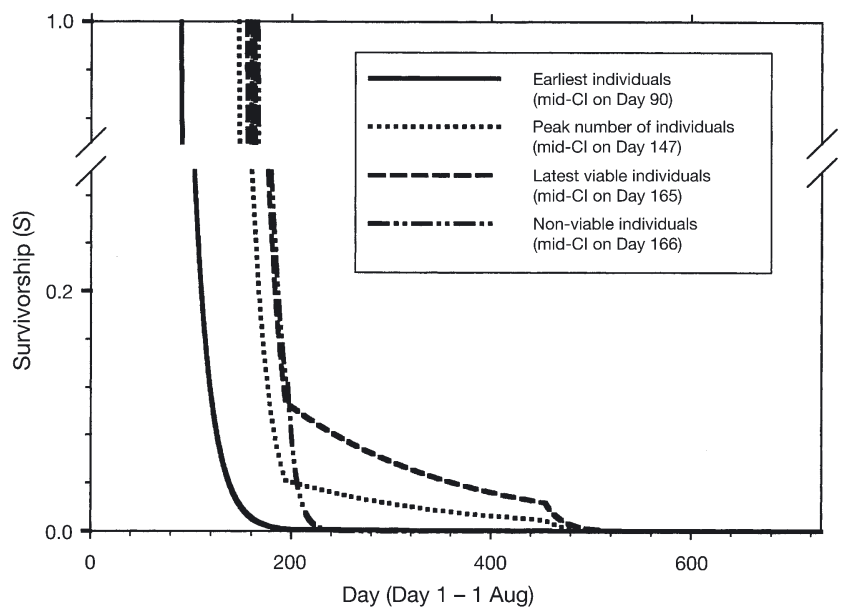

Fig. 4. Calanoides acutus. Mortality trajectories of individuals entering mid-CI stage on different dates. Mortality was $0.0585 \mathrm{~d}^{-1}$ during the epipelagic period (Days 90 to 195 ; Days 455 to 560 ) and $0.007 \mathrm{~d}^{-1}$ during for the remainder (the overwintering period) 
weight by the end of the second growing season. Individuals entering mid-CI more than a week after the recruitment peak were not able to gain enough weight to avoid starvation during the overwintering period. Nevertheless, those born just early enough to avoid starvation were capable of almost reaching maximum female weight by the end of the following season.

\section{Mortality of early copepodites}

The best fitting level of mortality during the epipelagic period for early stage copepodites (CI and CII) was $0.1 \mathrm{~d}^{-1}$. For stages CIII to adult, the best fit was achieved when the rate of mortality in the epipelagic was $0.0585 \mathrm{~d}^{-1}$. It was not possible to distinguish the relative contributions of starvation and predation during the epipelagic phase, although it is implicit that a rise to the surface increases the risk of predation. Mortality of $0.0585 \mathrm{~d}^{-1}$ virtually eliminated the earliest individuals by the time the population descended on 11 February (Day 195) (Fig. 4). Those individuals that were recruited into $\mathrm{CI}$ when numbers in this stage peaked were reduced to ca. $4 \%$ of their original number by the time of descent. The last day of recruitment into mid-CI before it became too late to amass enough resources for overwintering was 12 January (Day 165). Individuals that recruited into mid-CI on this day suffered the lowest amount of epipelagic mortality because they were only present in the epipelagic strata for the shortest possible amount of time. Nevertheless, this short period still reduced their original number to ca. $10 \%$. The rate of mortality dropped during the overwintering period. However, those individuals that arrived in mid-CI after 12 January suffered high mortality because they were insufficiently resourced and, consequently, starved. By the time the population reascended into the epipelagic the following spring, less than $2 \%$ of the individuals that arrived at mid-CI during the peak recruitment period remained. The probability that these individuals would survive a second year was less than $1 \%$.

\section{Life-cycle phenotypes}

Model populations that were dominated by the CV 1 yr phenotype generally achieved the best fit to the empirical observations (Table 3). The highest-ranking phenotypic composition was $70 \%$ CV 1 yr, $20 \%$ CIV $1 \mathrm{yr}$ and $10 \%$ CIV 2 yr (subjected to an epipelagic mortality rate of $0.0585 \mathrm{~d}^{-1}$; see below). Within the top 10 ranking model runs, $80 \%$ or more of the population completed their life cycle within 1 yr. Furthermore, individuals had a 70 to $80 \%$ chance of spending at least 1 overwintering period as a CV stage and only a 20 to $30 \%$ chance of remaining as a CIV when entering diapause.

The mortality rate experienced during the epipelagic period had a profound influence on the overall level of fit to the empirical data (Table 3). Almost all model runs that subjected the population to an epipelagic mortality coefficient of $0.0585 \mathrm{~d}^{-1}$ ranked higher, with respect to fit, than other runs with higher or lower coefficients. This value is 10 times the predation rate experienced by individuals during the overwintering stage,

Table 3. Calanoides acutus. Best-ranked phenotypic compositions (see 'Life-cycle phenotypes' for details) for the top 3 ranking epipelagic mortality rates. $\beta$ : mortality coefficient

\begin{tabular}{|c|c|c|c|c|c|c|c|c|c|}
\hline $\begin{array}{l}\text { Rank } \\
\text { (out of 2575) }\end{array}$ & $\begin{array}{l}\text { CIV } 1 \text { yr } \\
(\%)\end{array}$ & $\begin{array}{l}\text { CIV } 2 \text { yr } \\
(\%)\end{array}$ & $\begin{array}{c}\mathrm{CV} 1 \mathrm{yr} \\
(\%)\end{array}$ & $\begin{array}{l}\text { CV } 2 \text { yr } \\
(\%)\end{array}$ & $\begin{array}{l}1 \text { yr pheno- } \\
\text { type (\%) }\end{array}$ & $\begin{array}{c}2 \text { yr pheno- } \\
\text { type (\%) }\end{array}$ & $\begin{array}{c}\text { CV over- } \\
\text { winter (\%) }\end{array}$ & $\begin{array}{l}\text { CIV over- } \\
\text { winter (\%) }\end{array}$ & $\begin{array}{c}\beta \mathrm{d}^{-1} \text { epipelagic } \\
\text { period }\end{array}$ \\
\hline 1 & 20 & 10 & 70 & 0 & 90 & 10 & 70 & 30 & 0.0585 \\
\hline 2 & 30 & 0 & 60 & 10 & 90 & 10 & 70 & 30 & 0.0585 \\
\hline 3 & 10 & 10 & 80 & 0 & 90 & 10 & 80 & 20 & 0.0585 \\
\hline 4 & 30 & 0 & 70 & 0 & 100 & 0 & 70 & 30 & 0.0585 \\
\hline 5 & 20 & 0 & 70 & 10 & 90 & 10 & 80 & 20 & 0.0585 \\
\hline 6 & 20 & 0 & 80 & 0 & 100 & 0 & 80 & 20 & 0.0585 \\
\hline 7 & 10 & 20 & 70 & 0 & 80 & 20 & 70 & 30 & 0.0585 \\
\hline 8 & 0 & 20 & 80 & 0 & 80 & 20 & 80 & 20 & 0.0585 \\
\hline 9 & 20 & 10 & 60 & 10 & 80 & 20 & 70 & 30 & 0.0585 \\
\hline 10 & 10 & 10 & 70 & 10 & 80 & 20 & 80 & 20 & 0.0585 \\
\hline 20 & 0 & 30 & 70 & 0 & 70 & 30 & 70 & 30 & 0.05265 \\
\hline 21 & 0 & 30 & 60 & 10 & 60 & 40 & 70 & 30 & 0.05265 \\
\hline 22 & 10 & 20 & 70 & 0 & 80 & 20 & 70 & 30 & 0.05265 \\
\hline 269 & 0 & 50 & 50 & 0 & 50 & 50 & 50 & 50 & 0.04095 \\
\hline 282 & 10 & 40 & 50 & 0 & 60 & 40 & 50 & 50 & 0.04095 \\
\hline 283 & 0 & 50 & 40 & 10 & 40 & 60 & 50 & 50 & 0.04095 \\
\hline
\end{tabular}




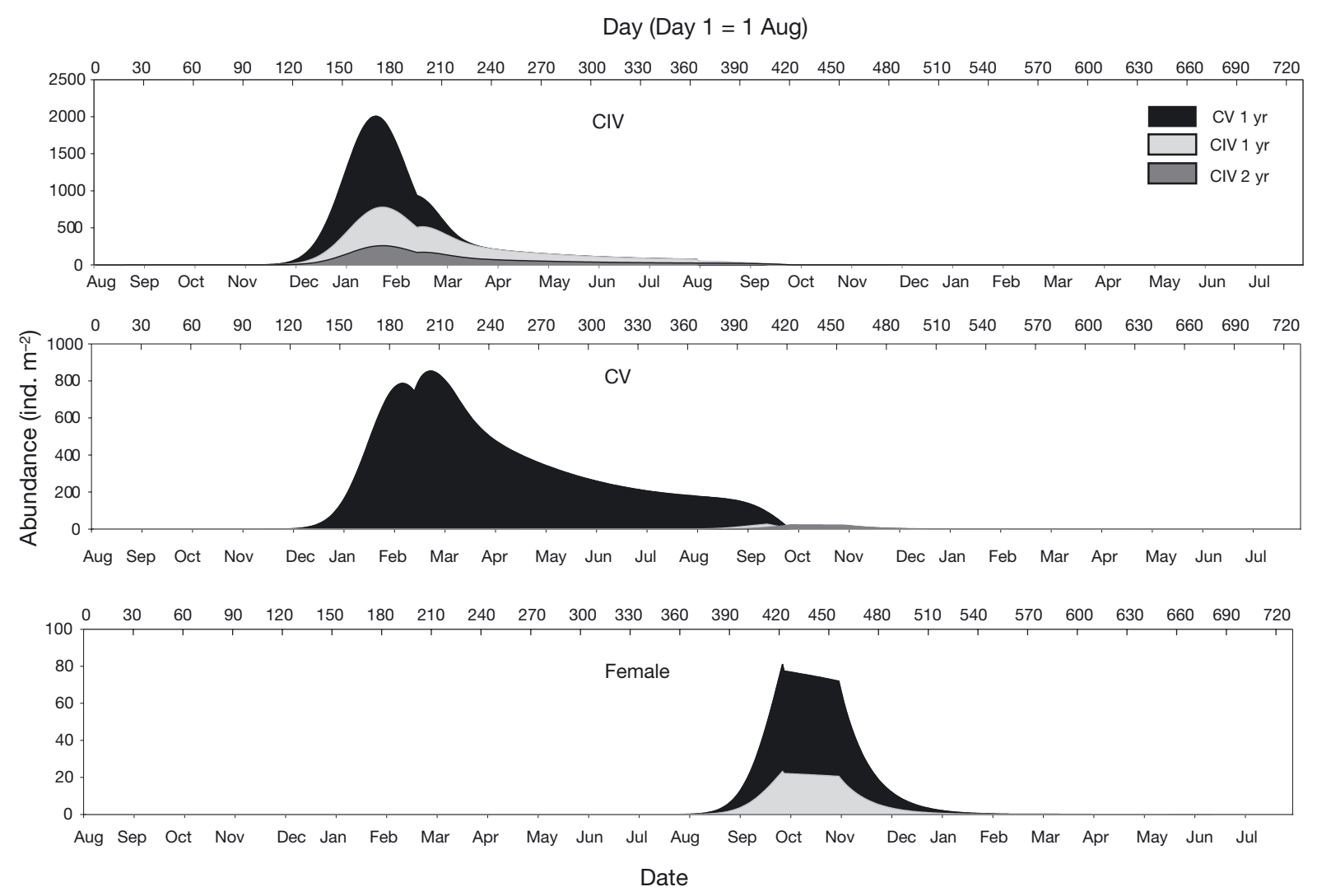

Fig. 5. Calanoides acutus. Predicted trajectory of stage abundance over the lifetime of the year class, using the phenotypic proportions and epipelagic mortality rate that achieved the best fit to observations

emphasising how making a seasonal descent reduces predation risk.

Fig. 5 follows the trajectory of a single year-class from CIV to adulthood, showing the relative contribution of the phenotypes to the total predicted abundances, assuming the best-fitting distribution of $70 \%$ CV 1 yr, $20 \%$ CIV 1 yr and 10\% CIV 2 yr. The CIV 1 yr and 2 yr phenotype starts to dominate the CIV population from 16 February (Day 200) and becomes the sole phenotype in this stage from around mid-March (Day 230). These phenotypes also make a small contribution to $\mathrm{CV}$ numbers at a time when most of the CV $1 \mathrm{yr}$ individuals have developed into adults. Therefore, the CVs observed between late September (Day 420) and late November (Day 510) are probably CIV 1 yr and 2 yr phenotypes.

The predicted trajectories of recruitment and decline over the course of the year are compared to empirical patterns in Fig. 6. The model predicted that the abundance of stages CII and CIII peaked on 30 December (Day 152) and 5 January (Day 158), respectively, and empirical abundances for both stages were particularly high around those periods. Numbers of CIV were pre- dicted to increase most rapidly from 28 December (Day 150) onwards, peaking on 21 January (Day 174), while observations of abundance in this stage rose dramatically between 7 January (Day 160) and 27 January (Day 180). Predictions on the subsequent decline of the CIV population, caused by a combination of mortality, development into the CV stage and sinking below the maximum depth of observation $(1000 \mathrm{~m})$, corresponded with the general trajectory suggested by the empirical data, and by mid-winter both predicted and observed abundances of CIV were ca. 100 ind. $\mathrm{m}^{-2}$. By spring (September onwards), the abundance of CIV declined in both predictions and observations until the start of recruitment into this stage, after 28 November. The predicted abundance trajectory of the CV stage was very similar to that of CIV, and the general pattern was similar to that present in the empirical data, apart from early summer, when observed values were higher than those predicted. Females were predicted to persist for around $150 \mathrm{~d}$, declining from ca. 100 ind. $\mathrm{m}^{-2}$ in October to negligible numbers by mid-February. Empirical values for female abundance were scattered above and below this predicted pattern. 


\section{Sensitivity analyses}

\section{Effects of altering model parameterisation}

Overwintering mortality. Atkinson et al. (1997) noted that their estimate of winter mortality may have been artificially high. This is because a proportion of the overwintering copepodites may have resided below the sampling depth during mid-winter. Therefore, model runs were performed to determine the effect of reducing overwintering mortality on model predictions. Mortality from predation was reduced to coefficients of either 0.003 and $0.001 \mathrm{~d}^{-1}$, whilst the rate of starvation was kept the same as before. This resulted in the overwintering population experiencing total overwintering mortality coefficients of 0.00415 or $0.00215 \mathrm{~d}^{-1}$, respectively. Altering the level of overwintering mortality made little difference to the phenotypic compositions showing the closest fit to observations (Table 4). As in the original run, the population was split between $70 \%$ overwintering as $\mathrm{CV}$ and $30 \%$ as CIV, the majority finishing their life cycle in $1 \mathrm{yr}$. Both the low $\left(0.00415 \mathrm{~d}^{-1}\right)$ and very low $\left(0.00215 \mathrm{~d}^{-1}\right)$ overwintering mortalities had a goodness of fit that ranked higher than the original runs, meaning that they fitted more closely to observations (Table 4). Altering the overwintering mortality had the greatest impact at the adult developmental stage (Fig. 7A). At a rate of $0.00215 \mathrm{~d}^{-1}$, the predicted abundance of females was 3 times that of the original model runs. With the original parameterisation, the predicted abundances fall below a large number of observations, whereas lower overwintering mortalities result in abundances closer to those observed. These results suggest that the true overwintering mortality in many years may well have been lower than estimated by Atkinson et al. (1997).

Period spent in the epipelagic layer. The epipelagic period is a time of high growth and high mortality risk. It is assumed that the exact duration depends on factors such as the length of the phytoplankton production season and the optimum trade-off between growing large enough to stave off overwintering starvation and not staying too long such that the probability of predation becomes too high. The duration of the epipelagic period was based on empirical observations averaged over the whole Scotia Sea. However, it is likely that the length of this period will alter interannually and regionally. We investigated the implications of this variation by increasing and decreasing the length of occupancy in the epipelagic period by $50 \mathrm{~d}$, $\pm 25 \mathrm{~d}$ at the start and end. The variation affected the model population in 2 ways, firstly, through altering the period over which epipelagic or overwintering predation was applied and, secondly, through altering potential period of growth, thus altering which part of the population suffered from starvation during overwintering.

Both increasing and decreasing the length of the epipelagic period altered the proportion of CIV to CV overwinterers relative to that predicted by the original
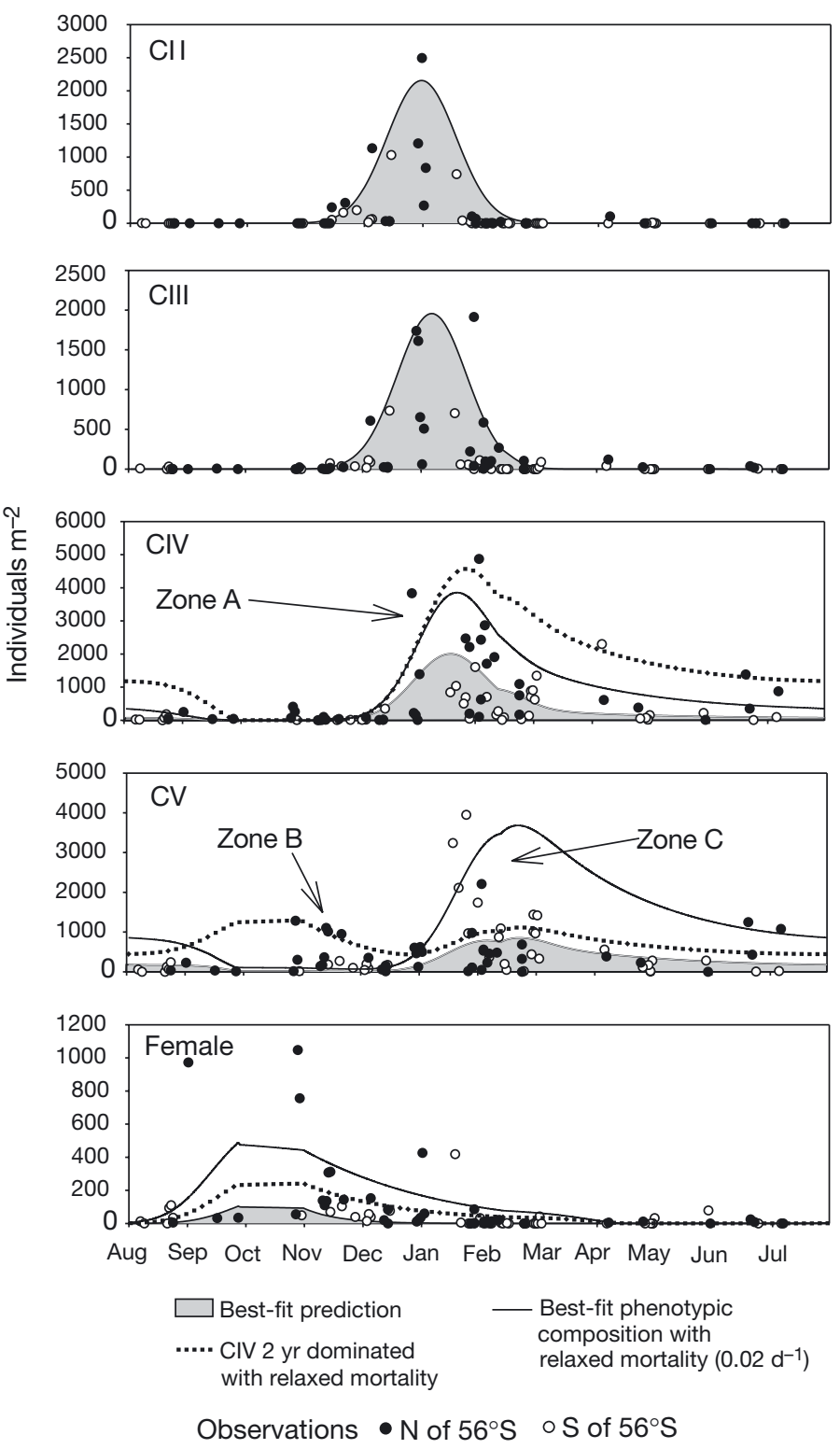

Fig. 6. Calanoides acutus. Predicted and observed abundance through the course of a year. Shaded area denotes the bestfitting prediction. Upper solid line shows the predicted abundances of stages at a lower rate of epipelagic mortality $\left(0.02 \mathrm{~d}^{-1}\right)$ in the late copepodite stages (using best-fit phenotypic composition). Upper dotted line is the abundance predicted if the CIV 2 yr phenotype (see 'Life-cycle phenotypes' for details) dominated the population and epipelagic mortality in late copepodite stages was lowered. Observations are coded to show whether their origin was in the north $(\bullet)$ or south (o) of the Scotia Sea (this was not taken into account within model runs) 
parameterisation (Table 4). If the period spent in the epipelagic region was longer than our best estimate, a population consisting of $80 \%$ CV 1 yr and $20 \%$ CIV 1 yr achieved the best fit to the empirical data. If the period was shorter, then a population with $40 \%$ CV 1 yr and $60 \%$ CIV 1 yr showed the closest fit. Nevertheless, both increasing and decreasing the period spent in epipelagic layers made the overall fit worse (Table 4).

Rate of growth. The rate of growth was estimated through fitting an exponential function through the mean weight of each stage versus time. One would expect the rate of growth in terms of weight to vary between years or sub-regions as a function of food availability. Furthermore, the data used to fit the func- tion used in this model contained many points from the South Georgia region, where food is generally considered to be more plentiful than in other areas of the Scotia Sea. Using alternative growth functions, representing good and bad years for growth, simulates the impact of this on population dynamics. In a good year, it was assumed that weights would be $25 \%$ higher than the mean, in a bad year, $25 \%$ lower. These growth rates can be approximated using growth exponents of 1.5 and 1.3, respectively (Fig. 1).

The rate of growth affects the weight at time of descent and the probability of starvation before reascent the following spring. Applying the low rate of growth did not achieve a better fit to observations com-

Table 4. Calanoides acutus. Results of the sensitivity analyses showing the top 3 model runs with respect to their level of fit to the observed data. Parameter altered in each of the sensitivity analyses is indicated in bold. See 'Life-cycle phenotypes' for details of phenotypic compositions. $\beta$ : mortality coefficient. Final column refers to the goodness of fit relative to the best fit in the original model run (expressed as a percentage; ' + ' signifying a better fit, ' - ' a worse fit).

\begin{tabular}{|c|c|c|c|c|c|c|c|c|c|}
\hline \multirow[t]{2}{*}{ Parameter } & \multirow[t]{2}{*}{ Rank } & \multirow[t]{2}{*}{$\begin{array}{l}\text { CIV } 1 \text { yr } \\
(\%)\end{array}$} & \multirow[t]{2}{*}{$\begin{array}{l}\text { CIV } 2 \text { yr } \\
(\%)\end{array}$} & \multirow[t]{2}{*}{$\begin{array}{l}\text { CV } 1 \text { yr } \\
(\%)\end{array}$} & \multirow[t]{2}{*}{$\begin{array}{l}\text { CV } 2 \text { yr } \\
(\%)\end{array}$} & \multirow{2}{*}{$\begin{array}{c}\beta \mathrm{d}^{-1} \\
\text { epipelagic } \\
\text { period }\end{array}$} & \multicolumn{3}{|c|}{$\begin{array}{l}\text { Goodness of fit relative to } \\
\text { the best original run (\%) }\end{array}$} \\
\hline & & & & & & & CIV & $\mathrm{CV}$ & Adult \\
\hline \multicolumn{10}{|l|}{ Overwintering mortality } \\
\hline \multirow[t]{3}{*}{ Very low $\left(0.00215 \mathrm{~d}^{-1}\right)$} & 1 & 10 & 20 & 70 & 0 & 0.0585 & +1.2 & -0.9 & +22.9 \\
\hline & 2 & 20 & 10 & 70 & 0 & 0.0585 & +1.2 & -2.0 & +25.2 \\
\hline & 3 & 10 & 20 & 60 & 10 & 0.0585 & +1.2 & -0.1 & +20.2 \\
\hline \multirow[t]{3}{*}{ Low $\left(0.00415 \mathrm{~d}^{-1}\right)$} & 1 & 20 & 10 & 70 & 0 & 0.0585 & +0.7 & -0.4 & +14.2 \\
\hline & 2 & 10 & 20 & 70 & 0 & 0.0585 & +0.7 & +0.3 & +11.6 \\
\hline & 3 & 30 & 0 & 60 & 10 & 0.0585 & +0.7 & -0.5 & +14.2 \\
\hline \multicolumn{10}{|l|}{ Epipelagic period } \\
\hline \multirow[t]{3}{*}{ Increased } & 1 & 20 & 0 & 80 & 0 & 0.05265 & -5.9 & +2.7 & -12.3 \\
\hline & 2 & 0 & 20 & 80 & 0 & 0.05265 & -5.9 & +2.9 & -13.5 \\
\hline & 3 & 10 & 10 & 80 & 0 & 0.05265 & -5.9 & +2.8 & -12.9 \\
\hline \multirow[t]{3}{*}{ Decreased } & 1 & 60 & 0 & 40 & 0 & 0.05265 & -148.3 & -9.3 & +1.3 \\
\hline & 2 & 60 & 0 & 40 & 0 & 0.0585 & -126.6 & -11.0 & -1.6 \\
\hline & 3 & 50 & 10 & 40 & 0 & 0.05265 & -148.3 & -8.9 & -0.4 \\
\hline \multicolumn{10}{|l|}{ Growth rate (in weight) } \\
\hline \multirow[t]{3}{*}{ Low } & 1 & 20 & 0 & 80 & 0 & 0.0585 & -0.6 & -0.2 & -2.1 \\
\hline & 2 & 10 & 10 & 80 & 0 & 0.0585 & -0.6 & +0.1 & -3.5 \\
\hline & 3 & 20 & 0 & 70 & 10 & 0.0585 & -0.6 & +0.1 & -3.5 \\
\hline \multirow[t]{3}{*}{ High } & 1 & 30 & 0 & 70 & 0 & 0.0585 & +0.8 & -1.5 & +6.1 \\
\hline & 2 & 20 & 10 & 70 & 0 & 0.0585 & +0.8 & -1.0 & +4.0 \\
\hline & 3 & 10 & 20 & 70 & 0 & 0.0585 & +0.8 & -0.5 & +1.9 \\
\hline \multicolumn{10}{|l|}{ Development temperature } \\
\hline \multirow[t]{3}{*}{$0^{\circ} \mathrm{C}$} & 1 & 10 & 10 & 80 & 0 & 0.05265 & +3.6 & -7.1 & +1.1 \\
\hline & 2 & 20 & 0 & 70 & 10 & 0.05265 & +3.6 & -7.1 & +1.1 \\
\hline & 3 & 0 & 20 & 80 & 0 & 0.05265 & +3.6 & -6.6 & -0.8 \\
\hline \multirow[t]{3}{*}{$5^{\circ} \mathrm{C}$} & 1 & 30 & 0 & 70 & 0 & 0.06435 & -1.9 & +4.9 & -0.3 \\
\hline & 2 & 20 & 10 & 70 & 0 & 0.06435 & -1.9 & +5.2 & -1.9 \\
\hline & 3 & 30 & 0 & 60 & 10 & 0.06435 & -1.9 & +5.2 & -1.9 \\
\hline \multicolumn{10}{|l|}{ Genotypic sex-ratio } \\
\hline \multirow[t]{3}{*}{$90 \%$ females; $10 \%$ males } & 1 & 20 & 10 & 70 & 0 & 0.0585 & 0 & 0 & +11.1 \\
\hline & 2 & 30 & 0 & 70 & 0 & 0.0585 & 0 & 0 & +13.5 \\
\hline & 3 & 10 & 10 & 80 & 0 & 0.0585 & 0 & 0 & +11.1 \\
\hline \multirow[t]{3}{*}{$10 \%$ females; $90 \%$ males } & 1 & 20 & 10 & 70 & 0 & 0.0585 & 0 & 0 & -13.9 \\
\hline & 2 & 30 & 0 & 70 & 0 & 0.0585 & 0 & 0 & -13.4 \\
\hline & 3 & 10 & 10 & 80 & 0 & 0.0585 & 0 & 0 & -13.9 \\
\hline
\end{tabular}


pared with the original parameterisation (Table 4). However, applying the higher rate of growth did achieve a better fit, most notably in predicting the abundance of females, which were higher than in the original run (Fig. 7B). This suggests that the potential for starvation during the overwintering period may have been overestimated in the original parameterisation of the model.

Effect of development rate. Development rate is likely to be different at the thermal extremes of the distribu-

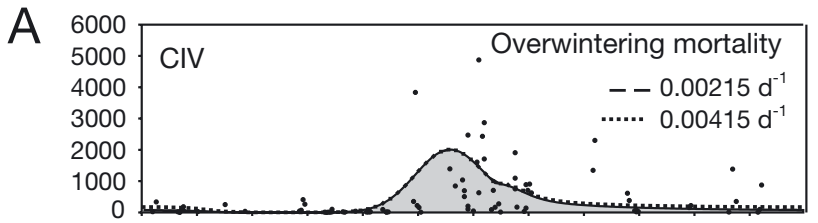

Aug Sep Oct Nov Dec Jan Feb Mar Apr May Jun Jul

$$
\text { है }
$$

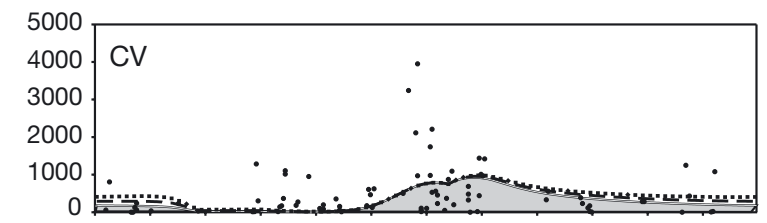

Aug Sep Oct Nov Dec Jan Feb Mar Apr May Jun Jul

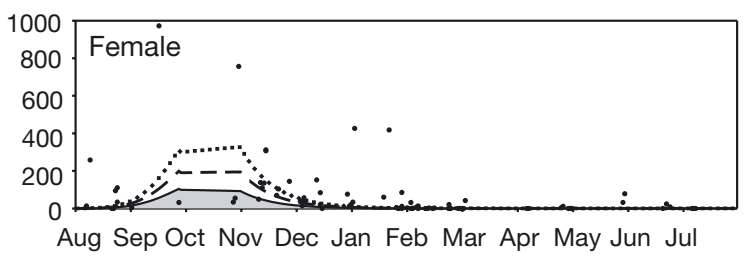

B 6000
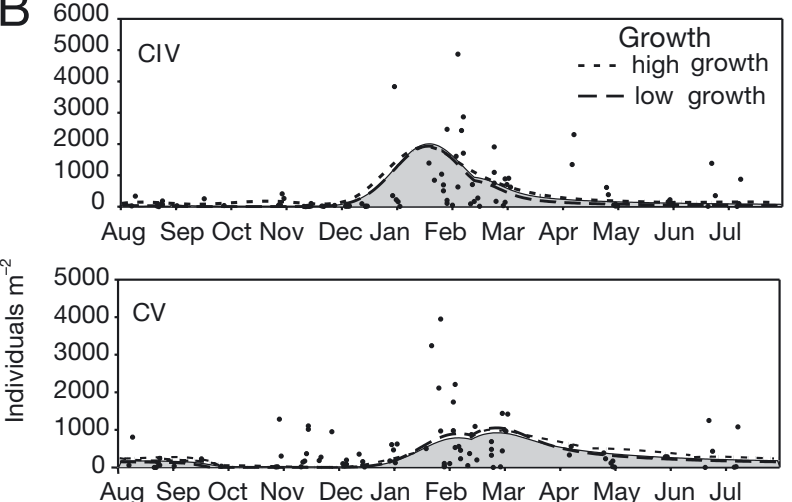

Aug Sep Oct Nov Dec Jan Feb Mar Apr May Jun Jul

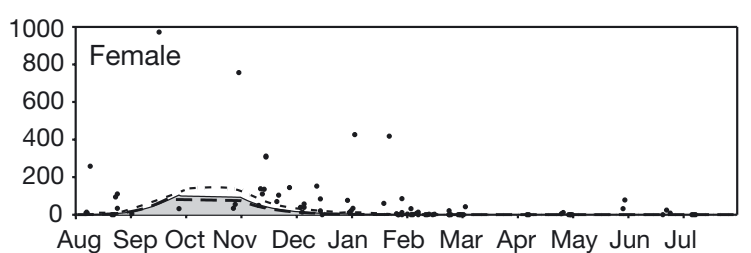

tional range of Calanoides acutus, given the well-established relationship between developmental time and temperature (e.g. Corkett et al. 1986). Alterations in this rate were estimated through applying a Bĕlehrádek function (Bělehrádek 1935) to experimentally derived stage durations. Ward \& Shreeve (1998) derived 3 constants: $a$ (slope for the response), $\alpha$ (temperature scale position of the response) and $b$ (exponent) for the embryonic duration of $C$. acutus. Using these constants, the developmental time of stage $i\left(D_{0}\right)$ at temperature $T_{0}$ was
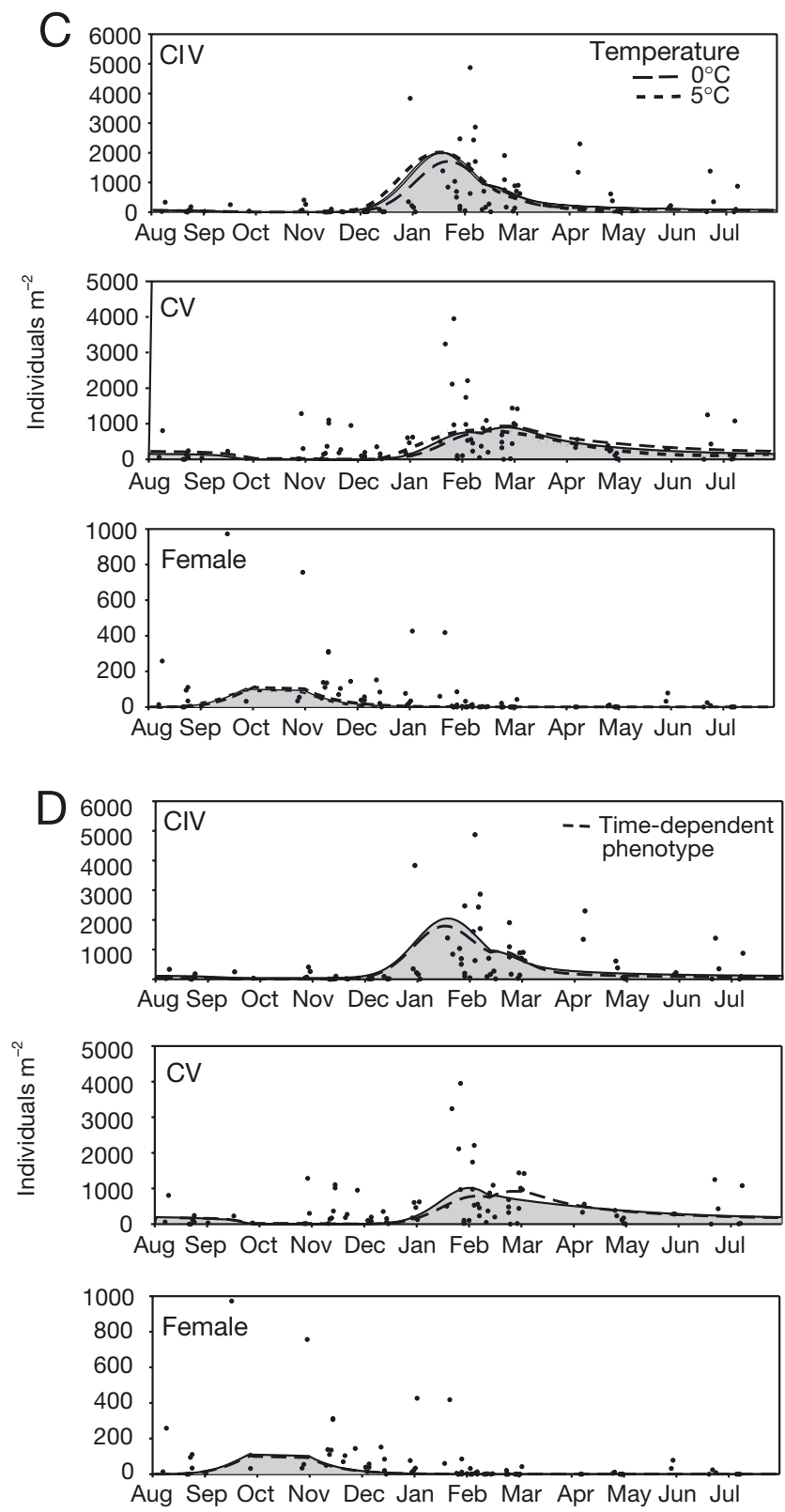

Fig. 7. Calanoides acutus. Abundance predicted by altering the original parameterisation of the model: (A) reducing overwintering mortality, (B) increasing and decreasing the rate of growth, (C) altering temperature to extremes found within the Scotia Sea, (D) making the phenotype of the population dependent on the date of spawn. Black dots denote observations; shading denotes original parameterisation 
estimated from a known development time of stage $i\left(D_{1}\right)$ at temperature $T_{1}$ with the equation:

$$
D_{0}=D_{1}\left[\frac{a\left(T_{0}-\alpha\right)^{b}}{a\left(T_{1}-\alpha\right)^{b}}\right]
$$

Development time between CI and CIV was reduced by $4 \mathrm{~d}$ at $5^{\circ} \mathrm{C}$ and increased by $5 \mathrm{~d}$ at $0^{\circ} \mathrm{C}$ in relation to average rate of development in the Scotia Sea. The mortality coefficient derived for the early copepodite stages was higher $\left(0.1 \mathrm{~d}^{-1}\right)$ than that derived for the later stages $\left(0.0585 \mathrm{~d}^{-1}\right.$; see above), so the reduction in development time at $5^{\circ} \mathrm{C}$ resulted in greater levels of survival (Fig. 7C). This illustrates the importance of the rate of mortality on the early copepodite stages on the overall recruitment success in any particular year. The model does not consider the higher metabolic rate that would result from higher temperatures, which would probably increase the risk of starvation over winter and so reduce population size.

Altering genotypic sex-ratio. There is great difficulty in determining the true genotypic sex-ratio in the population because males develop slightly earlier than females (Spiridonov \& Kosobokova 1997) and so would be exposed to higher mortality by the time the relative concentration of both sexes can be compared. Furthermore, males remain in the deeper part of the water columns while females move to the upper part, meaning that many net samples are biased towards the relative concentration of females. In the absence of accurate information, it was assumed that the genotypic sex ratio was $50 \%$ female and $50 \%$ male. It is necessary to test how important this assumption is to model predictions.

Two runs of the model were made, one in which the genotypic sex ratio was $90 \%$ female and $10 \%$ male, and the other with the reverse. Both runs showed that altering the sex ratio made little difference to predicted epipelagic mortality rate and life cycle phenotypic composition compared with the original model run (Table 4). This was because of 2 reasons. Firstly, the rate of mortality meant that only $2 \%$ or less of the population actually made it to adulthood, i.e. $1 \%$ female and $1 \%$ male. For one sex to make up $90 \%$ of the adult population at maturation would mean that $2 \%$ make it in to that stage, which is a relatively small difference compared to other parts of the life cycle. Secondly, the method of the model was to seek the optimal fit of mortality rate and phenotypic composition across all of the later stages. Therefore, such a slight alteration in the numbers of adults, according to the exact sex ratio, made little difference to the overall rankings. Increasing the sex ratio in favour of females improved the fit because it had the effect of increasing predicted female abundance, which was generally underestimated by the model.
The importance of sampling error

Errors may arise in the measurement of abundance from factors such as net sampling through avoidance, inefficient filtering and the patchiness of animals in their environment (Clutter \& Anraku 1968, Vanucci 1968, Steele 1978). These errors are difficult to quantify and so the use of net samples as absolute measures of abundance in the field must always be treated with caution. Our method compares model predictions with seasonal abundance measured by nets to discriminate between different parameter values used within a stage-structured model. The abundance values reported in observations probably contain a certain degree of error, and so it is important to establish how much any observational error might change model predictions.

Error was introduced into the empirical data set through adding or subtracting a certain amount to each data point. The amount was random and differed between data points, but it was constrained within a certain percentage of the original value, 5, 10 or $20 \%$, depending on the model run. The model was then run as described in the methods. The process was repeated between 50 and 100 times for each different level of permitted error.

The epipelagic mortality value of $0.0585 \mathrm{~d}^{-1}$ always gave the highest ranked fit to observations of late stage copepodites, as in the original model run, even at the $20 \%$ level of error. With respect to phenotypic composition, a $5 \%$ level of error made little difference to predictions. However, with an error of 10 or $20 \%$, a number of other phenotypic compositions were equally as close to empirical observations. A common theme in these alternative compositions was that $70 \%$ of the population spent their first winter as a CV and $30 \%$ as a CIV, as is the case for the best fit in the original model run (Fig. 8).

\section{Alternative hypotheses on determination of life-cycle phenotype}

Determination of phenotype according to sex. The model structure investigated all combinations of phenotypic ratios in seeking the best fit to observations. The best estimate determined by the model differs from the proportions advocated by Drits et al. (1994), who suggested that Calanoides acutus males have a 1 yr life cycle, whilst females live for 2 yr and develop into adulthood after their second year. Model runs were performed to examine the implications of the Drits hypothesis on C. acutus population dynamics. A total of $50 \%$ of the population was fixed to consist of 1 yr phenotypes, overwintering as a $\mathrm{CV}$ and maturing 
as males, whilst the other $50 \%$ had a 2 yr life cycle, spending their first winter as CIV, the second as CV and maturing as females. Epipelagic mortality was set at $0.0585 \mathrm{~d}^{-1}$ and all other parameters kept the same as in the original model run.

Although the predicted abundance of CIVs and CVs simulated patterns similar to the observations, the predicted abundance of females was unfeasibly small. This is because all females had to endure $2 \mathrm{yr}$ of mortality, which reduced their numbers considerably. The majority of females had 1 yr life cycles, whilst 2 yr olds only make up a relatively small fraction of female numbers in the best-fitting phenotypic composition. Therefore, it is unlikely that the Drits hypothesis is valid in the Scotia Sea.

Determination of phenotype according to date of spawning. The model assumed that the phenotype of an individual was independent of when it was

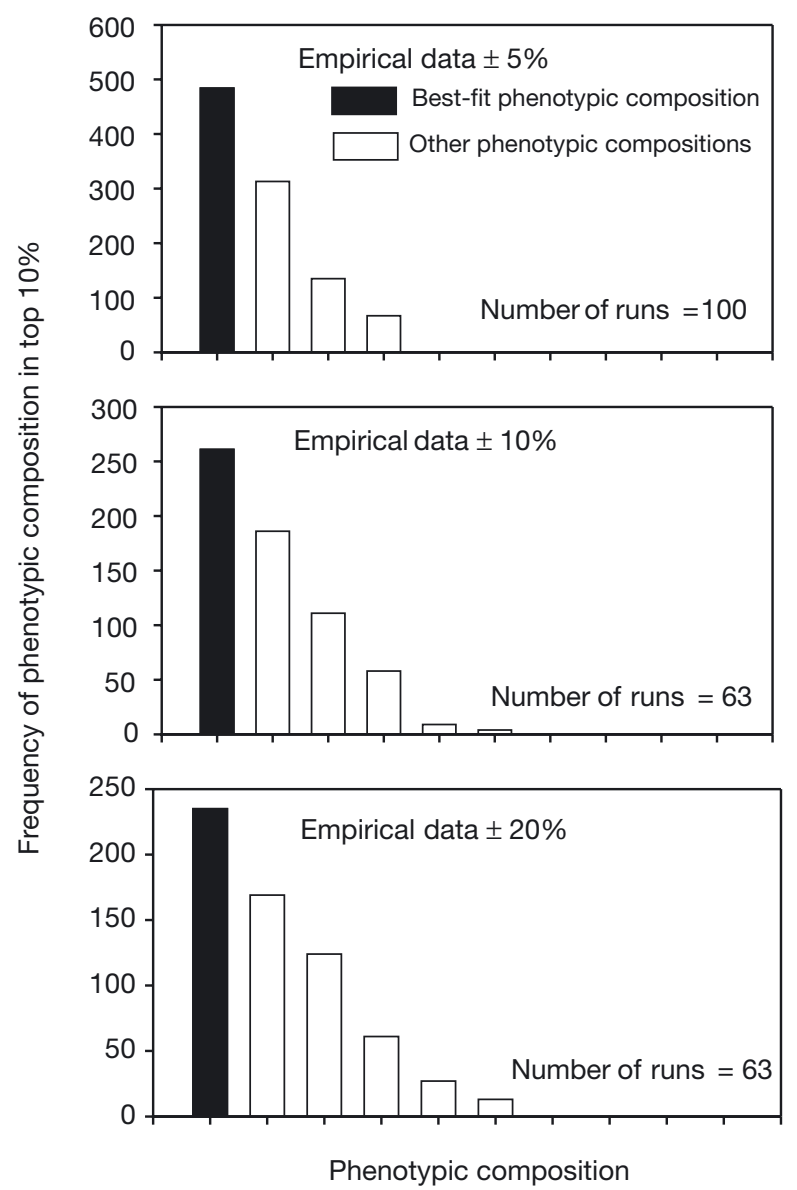

Fig. 8. Calanoides acutus. Frequency of different phenotypic compositions in the top $10 \%$ of ranks when different degrees of error were introduced into the empirical data set. Black column: phenotypic composition of $70 \%$ overwintering as a $\mathrm{CV}$ and $30 \%$ overwintering as CIV in the first year (i.e. best fit in the original model run) spawned. However, date of spawning may have an important influence on the success of different phenotypes. For instance, individuals spawned later in the year could save on the energy required for moulting and development and remain as a CIV, so increasing the level of overwintering reserves. To test this hypothesis, the CI population was divided into 3 overlapping normal distributions (Fig. 9), according to the proportions found to be the best fit in the original run, $70 \%$ CV 1 yr, 20\% CIV 1 yr and 10\% CIV 2 yr. The CV 1 yr proportion was designated as the first to be spawned, since they must reach the most advanced developmental stage by winter. The remaining 2 were nominally put in the order CIV $1 \mathrm{yr}$, CIV 2 yr, although the exact order had little bearing on the results. The main difference to the results of the original model was the comparatively earlier peak in CV numbers (Fig. 7D). This decreased the goodness of fit relative to that achieved by the original model.

Effect of latitude/region on phenotype. The empirical observations are drawn from the whole of the Scotia Sea, which covers latitudes between 48 and $66^{\circ} \mathrm{S}$. The model sought the best fit to the whole of the data set, so giving the most likely situation that, on average, would be encountered in any survey of this general area. Nevertheless, the large geographic distances between the north and south of the region may be a cause of some of the variation within the empirical data set. In Fig. 6, empirical observations were divided into those derived from the north of Scotia Sea (north of $56^{\circ} \mathrm{S}$ ) and those from the south (south of $56^{\circ} \mathrm{S}$ ). In the earlier stages (CII and CIII), observations from both the north and the south of the region showed similar levels of abundance and appeared to increase around the same time (i.e. between November and February). This indicates that patterns of recruitment were similar throughout the Scotia Sea. The majority of the

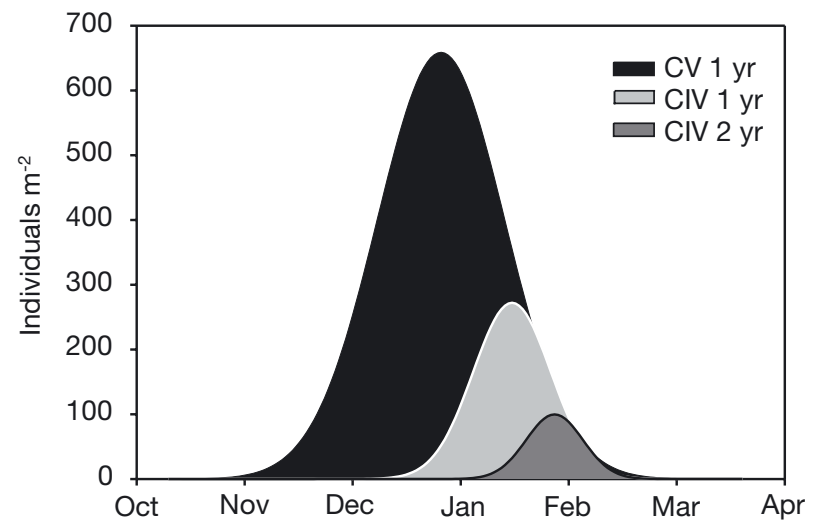

Fig. 9. Calanoides acutus. A theoretical pattern of the designation of life-cycle phenotype as if it were dependent on date of spawning 
observed abundances in the later stages also showed a great deal of overlap between north and south, indicating that the average pattern predicted by the model was equally applicable to both regions. Nevertheless, there were some interesting trends in the highest observed abundances. For instance, almost all of the high abundances observed in the CIV stage between November and February occurred in the southern region (Zone A; Fig. 6). Similarly, the high abundances observed in advance of the main annual recruitment to the $\mathrm{CV}$ stage (Zone $\mathrm{B}_{\text {; Fig. }}$ 6) also occurred in the south. By contrast, the highest CV abundances observed during the annual recruitment period (Zone $\mathrm{C}_{i}$ Fig. 6) occurred in the north.

The difference between the highest abundances in the north and south suggest that, in good years, the population reacts in different ways according to its location. In the north, the majority of the high $\mathrm{CV}$ abundances during the period of recruitment (Zone $\mathrm{C}$ ) can be explained by lower epipelagic mortality in that stage (Fig. 6). The phenotypic composition of the population does not alter from an average year, and remains dominated by CV 1 yr. In good years to the south, the same cannot be true, because only CIV abundance increases during the period of recruitment (Zone A), suggesting that many individuals remained as CIVs during their first year. Secondly, CV abundance was high after the period of maturation into adulthood but before the annual recruitment event (Zone B), indicating that these individuals must have a 2 yr life cycle. Combining these observations suggests that the CIV 2 yr phenotype becomes dominant in good years in the south. The dotted line in Fig. 6 shows the predicted stage abundances for a population dominated by this phenotype (note that epipelagic and overwintering mortality rate was dropped by $50 \%$ to simulate enhanced recruitment). It can be seen that both the high CIV abundances during recruitment (December to February) and the elevated levels of CV prior to this period are simulated well.

\section{DISCUSSION}

This study has shown that a variety of phenotypes exist in the Scotia Sea population of Calanoides acutus at any one time. It has predicted that a survey within this area would typically encounter a population in which $70 \%$ of the individuals overwinter as a CV stage and reach adulthood in $1 \mathrm{yr}$ whilst the remainder spend their first winter as a CIV stage and reach full maturity after either 1 or 2 yr. Individuals recruiting into the population would experience a mortality rate of ca. $0.1 \mathrm{~d}^{-1}$ during the CI and CII stages, dropping to $0.06 \mathrm{~d}^{-1}$ in the later stages. At the end of the productive season, individuals descend to depths greater than $500 \mathrm{~m}$ and enter a state of diapause, their mortality dropping by an order of magnitude in doing so. Those spawned too late in the productive season would be particularly susceptible to starvation, since there is not enough time to amass sufficient resources before descending. For other individuals, predation would be a more important cause of mortality during overwintering. Individuals completing their life cycle in 1 yr would dominate the female population the following spring, since the mortality endured by the 2 yr olds reduces their number to less than $1 \%$ of the adult population.

\section{Dependence of predictions on parameterisation}

The main features of the model were parameterised with independently measured functions to maintain robustness and applicability. The primary function of the sensitivity analyses was to determine the dependence of predictions on these functions. Two of the most crucial functions were those for the rate of development and growth. Both of these were derived from Shreeve et al. (2002), who carried out analyses in the South Georgia area. Corkett et al. (1986) showed that the development time of calanoid copepod stages varies equiproportionally with temperature. We used a Bĕlehrádek function to estimate rates at 0 and $5^{\circ} \mathrm{C}$, the 2 extremes that could be experienced within the Scotia Sea during the productive season. If the lower temperature were common during most of the observations, then a slightly lower epipelagic mortality rate $\left(0.053 \mathrm{~d}^{-1}\right)$ would have been predicted, whilst if the higher temperature were more prevalent, the predicted mortality rate would have been slightly higher $\left(0.064 \mathrm{~d}^{-1}\right)$. At both extremes, the CV $1 \mathrm{yr}$ remained the dominant phenotype, making up between 60 and $80 \%$ of the population. Growth rate was varied by assuming that the mean weight for a stage would be $25 \%$ higher in a good year and $25 \%$ lower in a bad year. Neither the epipelagic mortality rate nor the phenotypic compostion was altered to any great extent as a result of applying these alternative growth functions. Overall, the predictions of the model were not greatly altered by realistic variations in either development or growth rate.

Predictions of phenotypic composition were relatively sensitive to the duration of residency in the epipelagic layers. If the majority of observations were made in years where the epipelagic residency was $50 \mathrm{~d}$ shorter than our best estimate, then the best model fit was achieved by an even split in CIV 1 yr and CV 1 yr phenotypes. Making the epipelagic period longer had relatively little effect. A shorter productive season 
would be encountered with increasing latitude, and this model predicts that the proportion of CIVs would probably increase in more southerly latitudes, given that other features of the population dynamics are similar to the dataset considered here. In the Eastern Weddell Sea, to the south of the Scotia Sea, Atkinson et al. (1997) noted that CIV individuals were indeed more prevalent and that population increases appeared comparatively earlier. Fig. 6 shows that there would be peaks in CV earlier in the year if individuals that overwintered as CIV dominated the population. The capability of the model to reproduce features seen in other regions indicate that it contains many features that are more widely relevant.

Predictions of female abundance were most sensitive to the level of overwintering mortality. Atkinson et al. (1997) derived the value of $0.007 \mathrm{~d}^{-1}$ by comparing abundance levels between the start and end of the overwintering period. Much of their data only considered the 0 to $1000 \mathrm{~m}$ depth interval, although some samples during the winter considered depths between 0 and $1500 \mathrm{~m}$. Given that Andrews (1966) consistently found animals below $1000 \mathrm{~m}$, it is likely that some animals were missed by the Atkinson et al. (1997) study, which would lead to an overestimation of mortality. The predictions of female abundance by the present study mostly fell below observed abundances. Further runs with lower rates of overwintering mortality (e.g. $0.002 \mathrm{~d}^{-1}, 0.004 \mathrm{~d}^{-1}$ ) achieved better fits since they increased predicted adult abundance. Nevertheless, the best estimate of epipelagic mortality rate and phenotypic composition remained the same as in the original model, showing that the main outputs of the model were relatively insensitive to the exact rate of overwintering mortality.

Overwintering mortality was considered to arise from a combination of starvation and predation. The rate of starvation was determined by the rate at which individuals fell below the mean weight of a CIV stage. The rationale for this threshold was that lighter individuals do not exist, so they must have died of starvation. However, it is likely that there is also a 'point of no return' from which an individual cannot recover. We therefore probably underestimated the contribution of starvation mortality to total overwintering mortality. A suitable parameterisation of such a 'point of no return' has yet to be achieved, but would be beneficial to future model parameterisations.

\section{Variability in observations}

The model sought the best fit to the whole data set when choosing between different phenotypic compositions and mortality rates. It considered both low and high abundances and the highest ranked fits were achieved by trajectories that were mid-way between these extremes. It is likely that epipelagic mortality and/or phenotypic composition varied from the norm in some instances where high or low abundances were observed. Patchiness may also contribute to the degree of variability in the empirical data.

The model was parameterised to have the same mortality rate in all stages above CIII and throughout the entire epipelagic period. This was necessary to keep the number of variables to be fitted to levels that were computationally achievable. Fig. 6, however, suggests that there may have been different mortality rates both between stages and within seasons. In CV for instance, the deviance from the best fit was much more pronounced in January than at any other time. It seems likely that the mortality of CVs was more variable in January compared with other months. The same appears to be true in females in November and December. With regards differences between stages, the best-fit mortality rate appears to be too high in females compared with CIV and CV, given that predicted abundances for this stage are generally lower than most observations. It is possible that the genotypic sex ratio may be biased towards females rather than equiproportional, as was originally assumed. Further empirical research in this area would be of interest.

This study found that, on average, the rate of mortality of the latter stages of Calanoides acutus during the epipelagic period was around $0.06 \mathrm{~d}^{-1}$. This compares well with the rate of $0.07 \mathrm{~d}^{-1}$ calculated by Huntley et al. (1994) for CIV stages emerging from diapause in the Gerlache Strait. Surprisingly, the same study considered that the rate for $\mathrm{CV}$ was zero whilst that for CVI was extremely high $\left(0.131 \mathrm{~d}^{-1}\right)$. As the authors admit, zero mortality of CV seems unrealistic. Their model was parameterised assuming the entire population had a $1 \mathrm{yr}$ life cycle. The Gerlache Strait is south of the Scotia Sea and it would seem likely that at least $30 \%$ of the population had a 2 yr life cycle. The flux from CV into CVI was therefore less than they assumed, since many CV would remain in that stage. Since all CIV develop into $\mathrm{CV}$ after diapause, the flux into the $\mathrm{CV}$ stage would be higher than the flux out, so an increase in CV abundance would be expected if there were no mortality. This means that mortality must have been taking place, since CV abundance did not increase over the study period. Furthermore, a lower-than-assumed flux from CV to CVI means that CVI mortality rate was overestimated. Huntley et al.'s (1994) estimate of CIV mortality remains unaffected by this issue, since all individuals must moult into stage $\mathrm{CV}$ by the end of winter, and this was accounted for within their model.

One of the main patterns not explained by the majority of the sensitivity analyses was the increase in abun- 
dance of CVs in November and December. CVs that occur around this time must have a 2 yr life cycle, since they are too late to develop into adults and too early to be the result of that year's recruitment. Cumulative mortality would usually make the relative number of such individuals small within the population, so their high abundance in these instances suggests that a 2 yr phenotype must have been dominant in the population when these observations were made. Fixing the population so that it is dominated by the CIV 2 yr phenotype simulates well the high CV abundances observed in November and December (Fig. 6). The majority of empirical data points contributing to this pattern were from the southern Scotia Sea, so it seems feasible that, in certain years, regional conditions in the south favour the expression of a 2 yr phenotype. A similar finding was made by Spiridonov \& Kosobokova (1997), who showed that CIV was increasingly the dominant overwintering stage when moving from north to south in the Weddell Sea. The productive season becomes shorter with increasing latitude (Hart 1942, Voronina 1970) so it is possible that individuals run out of time to develop into CV before it ends and they descend. Remaining as a CIV over winter reduces their ability to reach adulthood by spring, so staying as a CV for another year may be the only feasible option. The puzzle with this strategy is that it reduces the probability of reaching adulthood, so it is likely that individuals adopt a less risky strategy through the whole of the life cycle, at the cost of not achieving the same rapid growth and development rate as their 1 yr counterparts. This may be achieved by remaining deeper in the water column during both the summer and winter months, which would result in a bi-modal vertical distribution of the population. Bathmann et al. (1993), for instance, observed that CVs occurred higher in the water column than CIVs during the winter, and were also closer to the sea surface during upward seasonal migration.

The high rate of epipelagic mortality reduces the number of individuals that were spawned early in the productive season to almost negligible amounts by the time of descent. This brings into question whether such individuals would remain in the epipelagic for the entire productive season, as opposed to descending to the deeper, safer layers when they have achieved a sufficient size to survive the winter. Parameterising the model around a fixed day of descent was based on the calculations of Atkinson et al. (1997), who showed that median depth of population was firmly centred in the epipelagic layers throughout the summer months. It is further supported by the data of Andrews (1966), which shows that a rapid descent is apparent. It is unlikely that all individuals remain in the epipelagic layers throughout the summer months, but the majority appear to descend almost synchronously. Such a pattern supports the hypothesis that the cue for descent is environmental rather than based on internal-state, but further physiological studies are required to make a better assessment of this important aspect of the life cycle.

\section{Time-dependence of life-cycle phenotypes}

The assumption made in the original model was that any phenotype could be spawned at any time during the productive season. This could either be because the organism's genotype is a strong determinant of its life-cycle strategy, or because the environmental factors that determine this phenotype vary in a relatively random fashion over the course of the productive season. The alternative scenario is that the environmental conditions that determine life-cycle phenotype alter gradually over the course of the season, such that they promote the development of some phenotypes at the start of the season, and others towards the end. For instance, individuals spawned earlier may have a greater probability of entering winter at an advanced stage (CV) and of completing their life cycle in $1 \mathrm{yr}$. The latest individuals would not reach $\mathrm{CV}$ by winter and may miss out on the chance to become an adult the following spring, so necessitating a 2 yr life cycle. Nevertheless, a population in which phenotype was determined by time of spawning did not achieve a level of fit as close to observations as the original model. Therefore, the assumption of phenotypic expression that is not time-dependent appears to be valid for the purpose of this modelling exercise. The true mechanisms underlying this expression are undoubtedly complex, and worthy of further investigation.

The Scotia Sea population of Calanoides acutus was dominated by individuals that diapause in the CV stage and mature the following spring. Nevertheless, ca. $30 \%$ of individuals diapause as a CIV stage, of which around a third mature into adults only in their second year. The effect of mortality means that those with a 1 yr phenotype will have a greater probability of making it to adulthood and contributing to the next generation. However, the persistence of the $2 \mathrm{yr}$ phenotype suggests that a gene for a 2 yr life cycle is maintained within the population. In a variable environment with a short productive season, a species with a 1 yr life cycle will undoubtedly show large oscillations in abundance inter-annually, as the population booms in good years and crashes in bad years. Even though the 2 yr phenotype may be less fit in an average year, over longer time-scales, its ability to withstand a bad year may allow it to persist in this region. 
This study has shown that it is possible to predict the most likely composition of life-cycle phenotypes in a population where a mixture exists. Furthermore, mortality rates during both the period in the epipelagic layers and during diapause over the winter can be estimated. The high rates of mortality predicted illustrates that individuals face a trade-off in terms of when to spawn and when to descend, so maximising their probability of making it to adulthood without starving during the long period of diapause. Examination of the physiological state of animals, especially energy reserves during the overwintering period, will allow better validation and refinement of model predictions.

Acknowledgements. We would like to thank officers and crew of the RRS 'James Clark Ross' and our colleagues within the DYNAMOE programme for their assistance in collection of data.

\section{LITERATURE CITED}

Andrews KJH (1966) The distribution and life-history of Calanoides acutus (Giesbrecht). Discov Rep 34:117-162

Atkinson A (1991) Life cycles of Calanoides acutus, Calanus simillimus and Rhincalanus gigas (Copepoda: Calanoida) within the Scotia Sea. Mar Biol 109:79-91

Atkinson A, Schnack-Schiel SB, Ward P, Marin V (1997) Regional differences in the life cycle of Calanoides acutus (Copepoda: Calanoida) within the Atlantic sector of the Southern Ocean. Mar Ecol Prog Ser 150:99-111

Bathmann UV, Makarov RR, Spiridonov VA, Rohardt G (1993) Winter distribution and overwintering strategies of the Antarctic copepod species Calanoides acutus, Rhincalanus gigas and Calanus propinquus (Crustacea, Calanoida) in the Weddell Sea. Polar Biol 13:333-346

Bĕlehrádek J (1935) Temperature and living matter. Protoplasma 8:1-277

Carlotti F, Giske J, Werner F (2000) Modeling zooplankton dynamics. In: Harris RP, Wiebe PH, Lenz J, Skjoldal HR, Huntley $M$ (eds) Zooplankton methodology manual. Academic Press, San Diego, p 571-667

Clutter RI, Anraku M (1968) Avoidance of samplers. In: Zooplankton sampling. UNESCO, Paris, p 57-76

Corkett CJ, McLaren IA, Sevigny JM (1986) The rearing of the marine calanoid copepods Calanus finmarchicus (Gunnerus), C. glacialis, (Jaschnov) and C. hyperboreus (Kroyer) with comment on the equiproportional rule. Syllogeus 58:539-546

Drits AV, Pasternak AF, Kosobokova KN (1994) Physiological characteristics of the Antarctic copepod Calanoides acutus during late summer in the Weddell Sea. Hydrobiologia 293:201-207

Eiane K, Aksnes DL, Ohman MD, Wood S, Martinussen MB (2002) Stage-specific mortality of Calanus spp. under different predation regimes. Limnol Oceanogr 47:636-645

Editorial responsibility: Otto Kinne (Editor),

Oldendorf/Luhe, Germany
Hart TJ (1942) Phytoplankton periodicity in Antarctic water. Discov Rep 11:261-356

Hopkins TL (1971) Zooplankton standing crop in the Pacific sector of the Antarctic. In: Llano GW, Wallen IE (eds) Biology of the Antarctic Sea, Vol 17. American Geophysical Union, Washington, DC, p 347-362

Huntley M, Escritor F (1991) Dynamics of Calanoides acutus (Copepoda, Calanoida) in Antarctic coastal waters. DeepSea Res Part A Oceanogr Res Pap 38:1145-1167

Huntley ME, Zhou M, Lopez MDG (1994) Calanoides acutus in Gerlache Strait, Antarctica. 2. Solving an inverse problem in population-dynamics. Deep-Sea Res II Top Stud Oceanogr 41:209-227

Lefkovitch LP (1965) The study of population growth in organisms grouped by stages. Biometrics 21:1-18

Mackintosh NA (1934) Distribution of the macroplankton in the Atlantic sector of the Antarctic. Discov Rep 9:65-160

Marin V (1988) Qualitative models of the life cycles of Calanoides acutus, Calanus propinquus and Rhincalanus gigas. Polar Biol 8:439-446

Pakhomov EA, Verheye HM, Atkinson A, Laubscher RK, Taunton-Clark J (1997) Structure and grazing impact of the mesozooplankton community during late summer 1994 near South Georgia, Antarctica. Polar Biol 18: 180-192

Pasternak AF, Kosobokova KN, Drits AV (1994) Feeding, metabolism and body composition of the dominant Antarctic copepods with comments on their life cycles. Russ J Aquat Ecol 3:49-62

Schnack SB Smetacek V, Bodungen BV, Stegmann P (1985) Utilization of phytoplankton by copepods in Antarctic waters during spring. In: Gray JS, Christiansen ME (eds) Marine biology of polar regions and effects of stress on marine organisms. John Wiley \& Sons, Chichester, p 65-81

Shreeve RS (2002) Growth of two species of Southern Ocean copepod in relation to their environment. $\mathrm{PhD}$, Open University, Milton Keynes

Shreeve RS, Ward P, Whitehouse MJ (2002) Copepod growth and development around South Georgia: relationships with temperature, food and krill. Mar Ecol Prog Ser 233: 169-183

Spiridonov VA, Kosobokova KN (1997) Winter ontogenetic migrations and the onset of gonad development in large dominant calanoid copepods in the Weddell Gyre (Antarctica). Mar Ecol Prog Ser 157:233-246

Steele JH (1978) Some comments on plankton patches. In: Steele JH (ed) Spatial patterns in plankton communities, Vol 3. Plenum Press, New York, p 1-20

Vanucci M (1968) Loss of organisms through the meshes. In: Zooplankton sampling. UNESCO, Paris, p 77-86

Voronina NM (1970) Seasonal cycle of some common Antarctic copepod spcies. In: Holdgate NM (ed) Antarctic ecology. Academic Press, London, p 162-172

Voronina NM (1978) Variability in ecosystems. In: Charnock $\mathrm{H}$, Deacon G (eds) Advances in oceanography. Plenum Press, New York, p 221-243

Ward P, Shreeve R (1998) Egg hatching times of Antarctic copepods. Polar Biol 19:142-144

Zar JH (1996) Biostatistical analysis. Prentice Hall, Englewood Cliffs, NJ

Submitted: June 18, 2003; Accepted: December 4, 2003

Proofs received from author(s): April 26, 2004 